\title{
Key tea beverage values driving tourists' memorable experiences: an empirical study in Hong Kong-style café memorable experience
}

\author{
Man Lai Cheung, Wilson K.S. Leung, Jun-Hwa Cheah, Kian Yeik Koay and \\ Bryan Cheng-Yu Hsu
}

\begin{abstract}
Purpose - Using consumption value theory, this study aims to examine the impact of tourists' perceived consumption value dimensions of tea beverages offered by Hong Kong (HK)-style cafés, including taste value, price value, health value and emotional value, on tourists' memorable experience (ME), satisfaction and revisit intention

Design/methodology/approach - Using an online survey, this study collected 225 usable data from tourists who had experience in visiting HK-style cafés. Partial least squares-structural equation modelling was used to examine the importance of tourists' value dimensions, including taste value, price value, health value and emotional value, on tourists' $M E$, satisfaction and revisit intention.

Findings - The results revealed that taste value, price value, health value and emotional value are significant predictors of tourists' ME in HK-style cafés, which in turn drive their satisfaction and revisit intention.

Research limitations/implications - This study focusses on a single context: HK-style cafés. Future research may enhance the generalisability of the findings by replicating the model in other countries with diverse cultures.

Practical implications - Tourism marketers may strengthen tourists' ME, satisfaction and revisit intention by promoting tea beverages as well as HK-style cafés. Tourism marketers are recommended to communicate taste value, price value, health value and emotional value of HK-style tea beverages, which in turn encourages tourists to learn about the features of tea beverages. Subsequently, it drives tourists' $M E$ and satisfaction, thereby strengthening their intention to revisit.
\end{abstract}

Originality/value - This study contributes to the tourism marketing literature by providing an understanding of the role of tea beverage value in driving tourists' $M E$, satisfaction and revisit intention. By empirically testing a research model, this study confirms that specific consumption value elements of tea beverages, namely, taste value, price value, health value and emotional value, are critical drivers in driving tourists' $M E$, satisfaction and revisit intention.

Keywords Consumption value theory, Memorable experiences, Hong Kong-style cafes, Milk tea, Hong Kong-style tea beverages

Paper type Research paper

\section{Introduction}

Consumption of tea beverages is acknowledged as one of the most important tourism activities in influencing tourists' attitudes and satisfaction towards a destination because of its cultural uniqueness (Gupta et al., 2020). Although local food (i.e. street food and ethnic food) is regarded as supportive resources in tourism (Mak et al., 2012), tea beverages are
Man Lai Cheung is based at Department of Marketing, The Hang Seng University of Hong Kong, Shatin, Hong Kong and Newcastle Business School, The University of Newcastle, Callaghan, Australia. Wilson K.S. Leung is based at the Division of Science,

Engineering and Health Studies, College of Professional and Continuing Education, The Hong Kong Polytechnic University, Kowloon, Hong Kong. Jun-Hwa Cheah is based at the School of Business and Economics, Universiti Putra Malaysia, Serdang, Malaysia. Kian Yeik Koay is based at the Department of Marketing, Sunway University, Subang Jaya, Malaysia. Bryan Cheng-Yu Hsu is based at the College of Sports and Recreation, National Taiwan Normal University, Taipei, Taiwan.

Received 31 August 2020 Revised 15 February 2021 12 April 2021

Accepted 12 April 2021

The authors are grateful for constructive comments offered by the anonymous reviewers. 
regarded as an integral part of traditions and customs of destinations, and hence, tea beverages' consumption is driven by tourists' interest in the history, tradition and culture of a destination, being intricately linked to tourists' positive affections (Gupta et al., 2020; Su et al., 2019). Arguably, consumption of tea beverages increases tourists' dining quality by evoking authentic experiences about local ethnicity, culture and identity of destinations and thereby strengthening their attachment towards the focal destinations (Cheng et al., 2012; Su et al., 2019). Given its importance, tourism marketers increasingly integrate activities about tea beverages with tourism to strengthen destination image. Prime examples include tea beverages appreciation in gardens, visiting tours and workshops related to culinary skills of tea beverages (Cheng et al., 2012; Gupta et al., 2020). Thus, a synergistic relationship between consumption of tea beverages and tourism is posited to be influential in strengthening competitive advantages of destinations (Su et al., 2019).

Hong Kong (HK)-style tea beverages (e.g. HK-style lemon tea, stocking milk tea and coffee with tea) stand out as one of the most important tea beverages in driving tourists' emotional attachment because of its symbolic meanings related to the mixtures of Western Chinese culture (Chan, 2019; Mak, 2020). For example, stocking milk tea is regarded as a tea beverage that impersonates the British-style milk tea with the unique mixture of tea leaves that creates a new flavour and being awarded as a hybrid beverage representing flexibility and diversity of HK culture (Mak, 2020). In a similar fashion, coffee with tea is a beverage mixing coffee and milk tea, being regarded as a harmonious combination that demonstrates how HK identity is embedded in the HK-style tea beverage (Chan, 2019). HK-style cafés integrate HK-style tea beverages with café experiences, by offering mixtures of Western Chinese tea beverages that represent the identity and local culture of Hong Kongers (Chan, 2019; Cheung, 2013; Mak, 2020). As such, tourists enjoy tasting tea beverages and experience the Western Chinese culture in HK-style cafés for their vacations (Lai, 2015).

Arguably, HK-style tea beverages are tourism products with strong cultural connotations, being regarded as an indispensable constituent of tourists' memorable experience (ME). ME is conceptualised as the post-event positive experiences in tourists' minds (Kim, 2018) being developed by meaningful experiences obtained from their tourism activities related to local culture (Wang et al., 2019). Experiences in tasting HK-style tea beverages are regarded as fruitful sources in evoking tourists' positive ME because the tea-making culinary skills commodify the unique local cultures of HK (Cheung, 2013; Mak, 2020). Subsequently, ME obtained from tasting HK-style tea beverages drives tourists' satisfaction towards the destinations, as well as revisit intention.

Drawing from the abovementioned, consumption value theory (CVT) is conceptualised as a theoretical framework to understand how different value dimensions contribute to tourists' choice behaviours in different ways (Yeap et al., 2019). Although prior studies address how tea beverages create value in events and festivals, such as tea gardens visiting, tea arts enjoyment and cultural events related to tea beverages (Cheng et al., 2012; Gupta et al., 2020), the specific focus on the importance of HK-style tea beverages from a value perspective in driving tourists' dining experiences and its subsequent business outcomes is yet to be explored. Indeed, research in tea beverages is still in its infancy, warranting empirical studies in examining how to integrate tea beverages with café experiences to drive positive outcomes in tourism sectors (Su et al., 2019).

Young Chinese tourists are particularly interested in HK-style tea beverages because they are heavy users of social media and being exposed to in-depth information about novelty, ethnicity and cultural heritage of tourism products, such as featured stories of "coffee with tea" and "silk-stocking milk tea" (Chan, 2019; Kim et al., 2018; Mak, 2020). Indeed, the cultural meaning of HK-style tea beverages and HK-style cafes are increasingly being promoted on social media platforms, especially for WeChat and Weibo in China (Chan, 2019; Tse and Zhang, 2013). Given the importance of young Chinese tourists in the spending on tea beverages, studying Chinese young tourists' preferences on HK-style tea 
beverages is warranted. To address the knowledge gaps, this study adopts CVT in the context of tea beverages of HK-style cafés to address the following research questions:

$R Q 1$. What is the impact of perceived consumption value of tea beverages offered by HK-style cafés on tourists' ME and satisfaction on HK-style cafés?

$R Q 2$. What is the impact of ME and satisfaction on tourists' revisit intention to HK-style cafés?

\section{Theoretical background and hypotheses development Food and beverages in tourism}

Food and beverages create meaningful experiences in tourists' minds by offering flavours, local culinary cultures and customs (Okumus, 2020). Although conventional tourism literature considers food and beverages as supporting resources and being useful in creating supportive tourism experiences, recent tourism literature posits that food and beverages are influential in creating symbolic meaning and pleasure in tourists' minds (Mak et al., 2012, 2013). Arguably, tourists' positive emotional experiences and visiting intention is driven by the novelty and cultural characteristics of food and beverages, such as ethnic food, organic food and local street food (Konuk, 2019; Mak et al., 2013; Yeap et al., 2019). As such, recent studies also argued that destination image is inextricably bound up with tourists' affective responses to food and beverages, emphasising the importance of taste, smell, freshness and novelty in driving tourists' positive perceptions towards the focal destination (Sthapit et al., 2019; Yeap et al., 2019).

Arguably, sensory attributes, taste, novelty and cultural value of food and beverages are regarded as important motivational factors driving tourists' food consumption during their trips (Mak et al., 2013). Concurrently, quality attributes and cultural value of tea beverages are regarded as important drivers in evoking tourists' positive emotions and thereby building tourists' positive perceptions of destinations (Gupta et al., 2020). Yet, tea beverages in tourism is a relatively new research area, and the understanding of motivational factors driving tourists' intention to consume tea beverages, along with its subsequent consequences in strengthening tourists' positive response is very limited. This justifies the examination of the relationship between sensory pleasure and tourists' ME, along with the impact of obligatory factors (e.g. taste value, convenience and health concerns) on tourists' satisfaction (Mak et al., 2013; Okumus, 2020).

\section{Tea beverages}

Tea beverage is made by pouring hot water on the dried leaves of the tea plant, which is being acknowledged as one of the integral parts of food service that contribute to the business success of restaurants and destinations (Gupta et al., 2020). Although tea beverages are included in food tourism studies, there are several differences between tea beverages and food. Food is considered as supportive resources in tourism, being inextricably bound up with its sensory appeals, such as taste, smell and quality (Mak et al., 2012). Tea beverages are regarded as meaningful drinks for tourists, being inextricably linked with its emotional value, as reflected by its cultural value (Gupta et al., 2020; Mak, 2020). Tea beverages are considered as one of the most representative cultural tourism products in Asian contexts (Cheng et al., 2012; Su et al., 2019), playing considerable roles in evoking tourists' pleasure and authentic experiences (Gupta et al., 2020). The appreciation of tea beverages is regarded as an intangible culture, as manifested by the understanding of its antiquity, ethnicity, cultural value and quality attributes, constituting various tourism activities, such as festivals about tea, tea beverages tasting and café experiences with tea beverages (Cheng et al., 2010; Gupta et al., 2020; Su et al., 2019). Notably, HK-style silk-stocking milk tea is the distinguished tea beverage in HK, 
representing the cultural heritage, local spirit and identity of HK (Mak, 2020). The HK-style silk-stocking milk tea is the tailor-made tea beverage offered by HK-style cafes, using special culinary skills to create a special strong taste by using the mixture of various types of tea dust from various Asian countries (Mak, 2020), and thus being intricately linked with tourists' ME.

\section{Memorable experience}

Seeking to develop sustainable competitive advantages in the experience economy (Kim, 2018), marketers have invested substantial resources in providing meaningful and pleasant hospitality services to tourists, aiming to create positive experiences in their minds (Kim, 2018). This justified the development of ME, which is being conceptualised as tourists' assessment of post-event experiences in tourism activities and hospitality services (Sthapit et al., 2019). ME is acknowledged as an important concept in tourism and hospitality literature, being regarded as a significant predictor of tourists' positive attitudes and behaviours (Sthapit et al., 2019; Wong et al., 2019).

Given its importance, scholars have developed conceptual frameworks to discuss the ways to create $\mathrm{ME}$, along with measurement scales to measure the components of $\mathrm{ME}$ in various contexts, including destinations (Kim, 2018), local food consumption (Sthapit et al., 2019) and cafes with featured experiences in coffee (Wang et al., 2019). It is generally agreed that ME is manifested by tourists' hedonic, refreshing, novel and meaningful experiences obtained from local culture (Kim, 2018; Wong et al., 2020), hospitality services, and beverages (Wang et al., 2019), playing a considerable role in driving tourists' positive behavioural intentions. Wong et al. (2019) applied the concept of ME in the ethnic minority tourism context, positing the importance of scenery experience in driving tourists' satisfaction and subsequently strengthening tourists' intention to revisit and referrals. Similarly, Wong et al. (2020) found the importance of scenery experience in driving tourists' referral intentions, which in turn strengthens their intention to visit other ethnic destinations in the future. Applied to the food tourism context, Sthapit et al. (2019) found the importance of experience co-creation and experience intensification in driving tourists' ME in local food and subsequently strengthening their hedonic well-being. Although extant literature focusses on the conceptualisation and measurement of ME (Kim, 2018; Sthapit et al., 2019; Wang et al., 2019), as well as how ME strengthens tourists' positive behavioural intentions (Wong et al., 2019, 2020), the importance of consumption value of tea beverages in driving tourists' ME and its subsequent behavioural intentions is yet to be explored. This justifies the discussion in the relationship between tourists' perceived consumption value on tea beverages and $\mathrm{ME}$.

\section{Consumption value theory}

Marketing scholars suggest that shopping choices customers make are heavily determined by the values of a product or service (Sweeney and Soutar, 2001). Sheth et al. (1991) have developed CVT to explain customer purchase choice behaviours from the perspective of multiple values. CVT posits that customer choice is a function of multiple consumption values; consumption values make differential contributions in any given choice situation; and consumption values are independent (Sheth et al., 1991). In other words, customer values are a set of relativistic preferences characterising individuals' experience and interaction with some objects (Holbrook, 1999), such as products (Sweeney and Soutar, 2001), and food and beverages (Yeap et al., 2019). In particular, different value dimensions contribute to consumers' behavioural intentions in a different way.

To date, Sweeney and Soutar (2001) have extended Sheth et al.'s (1991) work via modifying the theoretical framework of CVT, that is, looking into the three general dimensions, namely, functional, social and emotional value. Firstly, functional value evaluates the utility derived 
from product quality, expected performance and price (Sweeney and Soutar, 2001). Secondly, emotional value refers to the utility derived from customer feelings or affective states of a product (Sweeney and Soutar, 2001). Thirdly, social value refers to the utility derived from customers' perceptions about the social benefits and self-image that a product offers (Sweeney and Soutar, 2001).

Recent studies on food tourism investigated the influence of different values on customer attitudes towards local food. For instance, Yeap et al. (2019) proposed that travelers' attitudes towards Penang street food could be affected by taste and emotional value. Moreover, Ahmad et al. (2019) found that price value is the strongest determinant in affecting tourists' attitudes towards Pakistani ethnic food. More recently, Rousta and Jamshidi (2020) found that the taste, health, price and emotional value positively affected tourists' attitudes towards local food in Iran. Although extant research investigated the effects of various customer values on customer attitudes towards local food, the value dimensions of tea beverages in driving tourists' ME in the context of tea beverages of HKstyle cafés are yet to be explored. To bridge the above research gaps, this study aims to explore the impact of four dimensions of customer value to assess tea beverages, including taste value, price value, health value and emotional value on tourists' ME.

\section{Taste value}

Taste value refers to the quality and performance of food and beverages (Chole and Kim, 2018, p. 2), reflecting tourists' perceptions of the flavour, freshness and visual presentation of food and beverages (Chloe and Kim, 2018). Extant literature posits the importance of taste value in affecting tourists' behavioural intentions. For instance, Chloe and Kim (2018) found a positive relationship between taste value of food and beverages and tourists' intention to visit. Ahmad et al. (2019) found a significant relationship between taste value and attitudes towards ethnic food. Applied to the tea beverage context, taste value is strong when the tea beverages are perceived to be visually attractive, fresh and with good flavour (Gupta et al., 2020). Arguably, compared to other restaurants in the Chinese regions, tea beverages offered by HK-style cafes are regarded as tasty and appealing for tourists manifested by its flavour, quality, appearance and smell and thus play a considerable role in affecting tourists' behavioural intentions (Gupta et al., 2020; Lai, 2015). Indeed, tourists are motivated to search for beverages with taste value, being enjoyed when they experience beverages with good flavour, smell and appearance, which in turn creates a positive experience in tourists' minds (Mak et al., 2013; Sthapit et al., 2019). As such, taste value is being regarded as an important input for memories, justifying the following hypothesis:

H1. Taste value has a significant positive impact on tourists' ME.

\section{Price value}

Price value refers to the amount that consumers give up obtaining a product (Zeithaml, 1988, p. 10), being manifested by the subjective evaluation of the quality-price ratio of food and beverages (Mak et al., 2013). Arguably, tourists would seek food and beverages with reasonable prices, aiming to enjoy food and beverages that provide good value for money. Price value of food and beverages is affirmed as an influential factor driving tourists' perceptions towards food and beverages and restaurants (Konuk, 2019). Ahmad et al. (2019) found the importance of price value of ethnic food in driving tourists' attitudes towards service providers and the destination. Rousta and Jamshidi (2020) also confirmed the significance of price value of food in driving tourists' attitudes towards local food, which subsequently strengthens tourists' revisit intention.

Summing up, value-seeking tourists search for food and beverages with reasonable prices and make purchase decisions based on whether the price is acceptable (Konuk, 2019). 
Tourists enjoy consuming food and beverages at reasonable prices, and hence, price value is regarded as an important input for memories (Yeap et al., 2019). Thus, we hypothesise as follows:

H2. Price value has a significant positive impact on tourists' ME.

\section{Health value}

Health value of food and beverages is evaluated by the degree of safety and cleanliness (Chole and Kim, 2018. p. 2). Health-conscious tourists prevent food and beverages with possible undesirable consequences in health (i.e. hypersensitive reactions and digestive discomfort); hence, they will pay attention to their physical well-being in their decisionmaking processes, especially being motivated to enjoy food and beverages with healthy ingredient (Mak et al., 2013). Choe and Kim (2018) found the importance of nutrition benefits, cleanliness and safety issues of the food and beverages in driving tourists' positive perceptions. Rousta and Jamshidi (2020) confirmed the importance of health value obtained from evoking tourists' positive attitudes towards ethnic food. Overall, the importance of health value in strengthening tourists' positive attitudes towards the food and beverages is confirmed. Thus, we hypothesise as follows:

H3. Health value has a significant positive impact on tourists' ME.

\section{Emotional value}

Emotional value is conceptualised as tourists' affection derived from products or services that arouse feelings (Choe and Kim, 2018). Food and beverages offer joy, fun, excitement, relaxation and enjoyment as benefits for tourists, which in turn evokes positive affection and positive emotional responses (Ahmad et al., 2019; Lai, 2015). Zhang et al. (2019) affirmed the importance of emotional value generated from beverages in arousing tourists' positive attitudes in the café context. Choe and Kim (2018) confirmed that emotional value obtained from food and beverages, such as happiness, pleasure and excitement plays a considerable role in strengthening tourists' positive perceptions towards the restaurant. Yeap et al. (2019) confirmed the significance of emotional value obtained from food and beverages in driving tourists' positive attitudes towards the destination. Notably, tea beverages commodify the meaningful cultural value of destinations, and thus play a considerable role in evoking tourists' positive emotional experiences (Su et al., 2019). As such, it is reasonable to posit that emotional value aroused from tea beverages offered by HK-style cafes is influential in driving tourists' ME in HK-style cafes. Thus, we hypothesise as follows:

H4. Emotional value has a significant positive impact on tourists' ME.

\section{Satisfaction}

Satisfaction refers to tourists' overall perceptions on the fulfilment of the needs during service encounters, being determined by the differences between the expected and actual performance of service providers (Zhang et al., 2019). Arguably, tourists are satisfied when the tourism activities are refreshing and enjoyable, being inextricably linked to the experiences obtained in tourism activities and hospitality services (Kim, 2018). Zhang et al. (2019) found that tourists are satisfied when they experience outstanding food and services in cafes. Overall, it is argued that tourists' post-visit experiences are influential in affecting their evaluations on the quality of tourism services, which in turn drives satisfaction, justifying the following hypothesis:

H5. ME has a significant positive impact on tourists' satisfaction. 


\section{Tourists' revisit intention}

Tourists' revisit intention refers to tourists' willingness to return to the destination in the coming future (Yeap et al., 2019), being inextricably linked with tourists' experiences and satisfaction. Indeed, tourists are satisfied when the quality of services received in their visits has fulfilled their requirements and hence are more likely to revisit the focal destination in the future (Wong et al., 2019). Konuk (2019) confirmed the importance of satisfaction in strengthening tourists' revisit intention in the context of organic food restaurants. Overall, tourists' satisfaction is influential in driving their revisit intention, justifying the following hypothesis:

H6. Satisfaction has a significant positive impact on tourists' revisit intention towards HKstyle cafes.

In a similar vein, scholars recognise the importance of $\mathrm{ME}$ in driving revisit intention. For example, Lai (2015) found the importance of tourists' dining experiences in driving customer loyalty behaviours in the context of HK-style cafes. Notably, Kim (2018) found the importance of $\mathrm{ME}$ in driving destination brand image, satisfaction and revisit intention in the mind of tourists. Based on the findings, a positive relationship between ME and revisit intention is reasonable to be established. Thus, we hypothesise as follows:

H7. ME has a significant positive impact on tourists' revisit intention towards HK-style cafes.

\section{Methodology}

\section{Sampling procedures and data collection}

The target population of this study focusses on young Chinese tourists (aged from 18 to 40, comprising generations $Y$ and $Z$ ) who have visited HK-style cafés in HK. Young tourists were considered as one of the most important segments for tourism because they are more willing to spend their time to go travelling, as well as spending more resources in searching for ethnic food and drinks, compared to adult travellers (Yeap et al., 2019). This phenomenon is apparent in China where young Chinese tourists are involved in exploring tea beverages with novelty, sensory experience and ethnic cultural meaning, and thus their consumption of tea beverages during their trips is increasing (Chan, 2019; Chang et al., 2010). Reportedly, China continues to lead the global outbound travel market with fast growth in tourism expenditure, with more than 150 million outbound tourists in 2019, almost three times increase in the last decade (Textor, 2020). As young Chinese tourists have their specific preference for gastronomy tourism, understanding how consumption value dimensions drive their perceptions of destinations is warranted (Mak, 2020). As such, young Chinese tourists are selected as the targeted respondents of this study.

Applying a purposive sampling method, we distributed online surveys through the platform called So-Jump (wxj.cn) to collect data from young tourists in China. To encourage participation, each of the valid respondents was awarded points or gifts after finishing the survey. To be eligible as our respondents, they must have prior experience in drinking tea beverages in HK-style cafés. Participants without experience in drinking tea beverages in HK-style tea cafes in HK were excluded from the study. Respondents were required to answer the questions based on their most familiar HK-style cafés, such as Tsui-Wah, TaiHing, Man-Wah Café and Chrisly Café. They also need to choose their most familiar tea beverages in HK-style cafés, such as lemon tea, milk tea and coffee with tea as stimuli to answer the questions.

Questionnaires were disseminated to 324 young Chinese tourists from March 2020 to April 2020, using popular social media platforms in China, including WeChat, Weibo and Tencent QQ. During the data collection process, 302 young Chinese tourists agreed to participate. However, 56 of the respondents reported that they did not have experience in HK-style tea 
beverages in HK; hence, their responses were discarded. Finally, this study also discarded 21 incomplete surveys; thus, 225 final usable responses were used for data analysis.

\section{Measurement instruments}

We used measurement items adapted from prior studies to measure all the constructs in the proposed research model (Table 2). The measurement items of tourists' consumption value dimensions towards tea in HK-style cafés were adapted from the studies of Ahmad et al. (2019) and Yeap et al. (2019). Price value, emotional value, taste value and health value were measured with three items. A four-item scale by Kim (2018) was used to measure ME. Satisfaction on HK-style cafés and revisit intention were measured by three items adapted from the study of Lai et al. (2019) and four items adapted from the study of Yeap et al. (2019), respectively. The content validity of the measurement items was checked by three experienced scholars and two practitioners in the area of tourism marketing and was confirmed by a pretest with a group of young Chinese tourists. Using the back-translation approach, the survey was first drafted in English and back-translated into Chinese to ensure consistency in meaning (Brislin, 1970).

\section{Results and data analysis}

\section{Respondents' profiles}

The background information of the 225 respondents was presented in Appendix 1. The sample comprised males (39.1\%) and females (60.9\%), who were aged from 18 to 40 years. The majority of the respondents were aged between 26 and 33 years (68.4\%), and more than $81 \%$ of them were bachelor graduates or above. All respondents had experience in visiting HK-style cafes and tasting HK-style tea beverages. Overall, the sample profile is deemed to be appropriate for this research.

\section{Data analysis}

We used partial least squares-structural equation modelling (PLS-SEM) to analyse the collected data. PLS-SEM is suitable for this study because it is suitable for studies with a large number of constructs, and it can be used to do exploratory research with the combination of explanatory and prediction (Hair et al., 2017).

\section{Common method bias assessment}

As this study uses a cross-sectional design, common method bias (CMB) was assessed. Harman's single-factor test appears to be of no concern as the first factor accounted for $40.7 \%$ is less than the $50 \%$ threshold (Podsakoff et al., 2003). Additionally, we assessed the full collinearity test recommended by Kock and Lynn (2012). The results revealed that the variance inflation factors were lower than 3.3, thus indicating the absence of CMB in this study.

\section{Measurement model assessment}

The reliability and convergent validity of the measurement model were first assessed. Reliability and convergent validity were deemed to be acceptable when factor loadings and composite reliability (CR) were higher than 0.70 , and average variance extracted (AVE) was higher than 0.50 (Hair et al., 2017). During the purification process, three items were dropped due to item loadings and AVE levels to achieve a valid and reliable instrument. As presented in Table 1, the factor loadings of all remaining measurement items exceeded 0.70 , whereas CR of all constructs exceeded 0.70, and AVE of all constructs exceeded 0.50 , thus confirming reliability and convergent validity. 
Table 1 Measurement model results

\begin{tabular}{|c|c|c|c|c|}
\hline Measurement items & Loadings & t-values & $C R$ & AVE \\
\hline Taste value & & & 0.779 & 0.639 \\
\hline Tea beverage offered by Hong Kong-style café is tasty & 0.805 & 13.900 & - & - \\
\hline Tea beverage offered by Hong Kong-style café is of good quality & 0.793 & 13.141 & - & - \\
\hline Emotional value & & & 0.825 & 0.611 \\
\hline Tea beverage offered by Hong Kong-style café makes me feel happy & 0.831 & 16.059 & - & - \\
\hline Tea beverage offered by Hong Kong-style café gives me pleasure & 0.774 & 11.249 & - & - \\
\hline Tea beverage offered by Hong Kong-style café makes me feel excited & 0.737 & 10.159 & - & - \\
\hline Health value & & & 0.855 & 0.747 \\
\hline Tea beverage offered by Hong Kong-style café is hygienic (clean) & 0.888 & 20.282 & - & - \\
\hline Tea beverage offered by Hong Kong-style café is healthy & 0.840 & 15.457 & - & - \\
\hline Price value & & & 0.905 & 0.762 \\
\hline Tea beverage offered by Hong Kong-style café is reasonably priced & 0.877 & 32.773 & - & - \\
\hline Tea beverage offered by Hong Kong-style café offers value for money & 0.922 & 74.871 & - & - \\
\hline The price of the tea beverage offered by Hong Kong-style café is appropriate & 0.816 & 18.947 & - & - \\
\hline ME & & & 0.800 & 0.572 \\
\hline I really enjoyed the experiences in Hong Kong-style café & 0.771 & 19.668 & - & - \\
\hline I had a chance to closely experience the local culture by visiting & 0.729 & 12.369 & - & - \\
\hline I experienced something new during visiting Hong Kong-style café & 0.768 & 17.281 & - & - \\
\hline Satisfaction & & & 0.841 & 0.638 \\
\hline My overall experience was satisfied in Hong Kong-style cafés & 0.816 & 30.363 & - & - \\
\hline My overall experience was pleased in Hong Kong-style cafés & 0.789 & 22.993 & - & - \\
\hline My overall experience was contended in Hong Kong-style cafés & 0.792 & 20.851 & - & - \\
\hline Revisit intention & & & 0.850 & 0.586 \\
\hline I would like to revisit Hong Kong-style cafés in the coming future & 0.805 & 28.187 & - & - \\
\hline I plan to revisit Hong Kong-style cafés in the coming future & 0.751 & 17.887 & - & - \\
\hline I will make an effort to revisit Hong Kong-style cafés in the coming future & 0.764 & 17.356 & - & - \\
\hline Hong Kong-style cafés could become my first choice in vacation & 0.739 & 19.153 & - & - \\
\hline
\end{tabular}

Discriminant validity was checked via Heterotrait-Monotrait ratio (HTMT) criterion. The values of the HTMT ratio of all the constructs were smaller than the threshold value of 0.85 (Table 2), thus further corroborating the discriminant validity (Hair et al., 2017).

\section{Structural model assessment}

Next, we examined the structural model. As presented in figure 1, all the seven hypotheses were accepted. Particularly, the impact of taste value on ME was the strongest $(\beta=0.259$, $p=0.000)$, followed by price value $(\beta=0.213, p=0.000)$, emotional value $(\beta=0.161, p=$ $0.014)$ and health value $(\beta=0.134, p=0.039)$. The results also revealed that $\mathrm{ME}$ has significant impact on tourists' satisfaction $(\beta=0.481, p=0.000)$ and revisit intention $(\beta=$ 0.397, $p=0.000)$. Lastly, the positive relationship between satisfaction and revisit intention was also strong and significant $(\beta=0.376, p=0.000)$.

\section{Table 2 Discriminant validity}

Emotionalvalue Health value ME Pricevalue Satisfaction Revisitintention Taste value

\begin{tabular}{|c|c|c|c|c|c|c|c|}
\hline Emotional value & - & - & - & - & - & - & - \\
\hline Health value & 0.191 & - & - & - & - & - & - \\
\hline ME & 0.417 & 0.471 & - & - & - & - & - \\
\hline Price value & 0.215 & 0.386 & 0.466 & - & - & - & - \\
\hline Restaurant Satisfaction & 0.435 & 0.311 & 0.683 & 0.197 & - & - & - \\
\hline Revisit intention & 0.365 & 0.231 & 0.799 & 0.215 & 0.748 & - & - \\
\hline Taste value & 0.599 & 0.660 & 0.782 & 0.417 & 0.734 & 0.553 & - \\
\hline
\end{tabular}




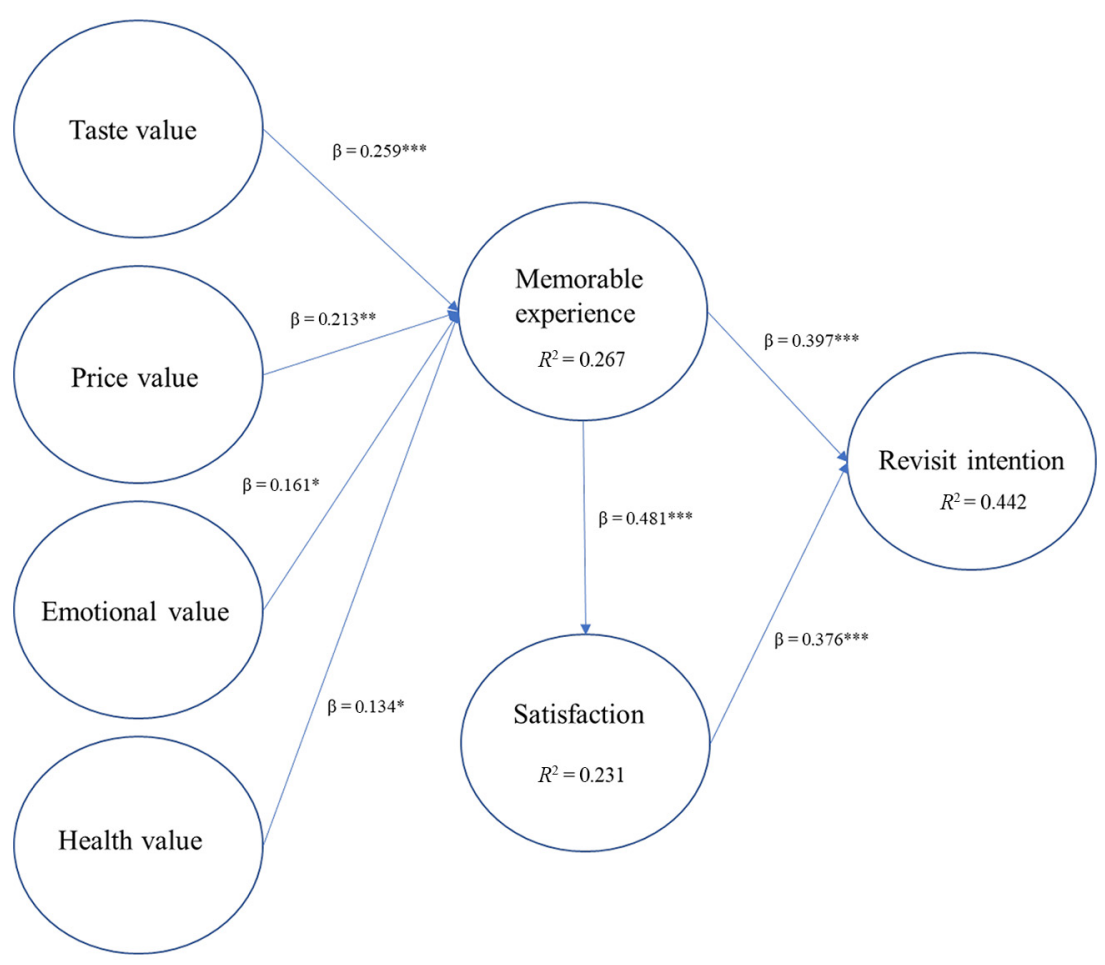

Notes: Paths significant at ${ }^{*} p<0.05 ;{ }^{* *} p<.01 ;{ }^{* *} p<0.001$ (one-tailed test)

Additionally, the explanatory power of the research model was assessed using the coefficient of determination, $R^{2}$ values. The values of $R^{2}$ of $\mathrm{ME}\left(R^{2}=0.253\right)$, satisfaction $\left(R^{2}=0.228\right)$ and revisit intention $\left(R^{2}=0.437\right)$. Thus, the results revealed that a meaningful amount of variation in the endogenous variables was accurately explained by the exogenous variables.

Moreover, we also checked the effect sizes $\left(f^{2}\right)$ of the paths using Cohen's (1988) criteria, that is, $f^{2} \geq 0.35$ (large effect), $f^{2} \geq 0.15$ (medium effect) and $f^{2} \geq 0.02$ (small effect). The results revealed that the effect sizes of $\mathrm{ME}\left(f^{2}=0.217\right)$ and satisfaction $\left(f^{2}=0.195\right)$ in explaining revisit intention were moderate, whereas the effect sizes of taste value $\left(f^{2}=0.070\right)$ and price value $\left(f^{2}=0.054\right)$ in explaining ME were weak. Lastly, the effect sizes of emotional value $\left(f^{2}=0.031\right)$ and health value $\left(f^{2}=0.020\right)$ had just exceeded the cut-off value.

Furthermore, the blindfolding procedure was used to assess the research model's predictive relevance $\left(Q^{2}\right)$. The results revealed that the values of $Q^{2}$ in each model were greater than zero, confirming that the exogenous latent variables are good enough to predict endogenous variables, thereby affirming the predictive relevance of the model (Hair et al., 2017). To corroborate these findings, this study also uses PLS-Predict technique (Shmueli et al., 2019). The root mean square error (RMSE) results revealed that the value of all indicators of revisit intention in the linear regression model was smaller than the PLS model, suggesting that the predictive power of revisit intention has high predictive power. Additionally, the value of majority indicators of ME and satisfaction in the linear regression model was smaller than the PLS model, suggesting medium predictive power in ME and satisfaction. Overall, the results suggested that the research model has predictive power when predicting new observations in the context of revisit intention towards HK-style cafés (Appendix 2). 


\section{Discussion of findings}

The results of this study confirm the importance of tourists' perceived consumption value on tea beverages in driving ME in HK-style cafes. In particular, taste value was found to be the strongest predictor of tourists' ME, suggesting that tourists emphasise the taste of tea beverages and prefer to consume tea beverages with appealing flavours and good quality. Price value was also found to be a significant predictor of tourists' ME, suggesting that value-conscious tourists believe that tea beverages offered by HK-style cafes offer good value for money. Emotional value also plays a considerable role in driving ME, suggesting that tourists prefer to have tea beverages that can help them to enjoy psychological relaxation, which in turn drives their ME. The significant positive relationship between health value and ME suggests that tourists also pay attention to the safety issues and cleanliness, preferring to have tea beverages with nutrition and good value for health.

Additionally, the findings of this study also suggest that ME has a significant positive impact on satisfaction in the context of HK-style tea beverage, suggesting that tourists are satisfied when they experience the enjoyable local culture by tasting tea beverages in HK-style cafes. Lastly, our findings also reveal the importance of ME and satisfaction in driving revisit intention, suggesting that when the experiences obtained from tea beverages are enjoyable and unforgettable, tourists are more satisfied, and they will be more willing to revisit HK-style cafes in the coming future.

\section{Theoretical implications}

This study provides several theoretical contributions. Firstly, this study makes substantial contributions to tourism marketing literature by exploring the importance of key consumption value dimensions in the setting of tea beverages offered by HK-style cafes. Applying CVT, prior studies explored the importance of price value and health value in driving tourists' satisfaction and loyalty to local food (Lai, 2015; Mak et al., 2013; Rousta and Jamshidi, 2020); this study contributes to theory advancement by highlighting the importance of taste value, health value, price value and emotional value of HK-style tea beverages in creating sensory pleasure for tourists, which in turn drives ME. Comparing with local food (i.e. driven by functional attributes, as manifested by price and health value), tea beverages consumption is driven by functional attributes (i.e. taste, health and price values), as well as its symbolic and cultural meanings that evoke emotional value (Jolliffe, 2007).

Secondly, the results of this study provide empirical evidence that demonstrates the comparative influences of tourists' perceived consumption value dimensions in driving tourists' ME in HK-style cafes. Although prior studies in the area of tea tourism emphasise the importance of cultural value in driving tourists' perceived destination image (Cheng et al., 2012; Gupta et al., 2020), this study contributes to the tourism marketing literature by confirming that taste value is the most important factor driving tourists' ME, followed by price value, emotional value and health value, thus suggesting the relative importance of CVT dimensions in the context of tea beverages offered by HK-style cafes.

Lastly, this study contributes to tourism literature by examining antecedents and consequences of ME. Although recent studies have attempted to examine the importance of ME in driving tourists' behavioural intentions in various contexts, such as ethnic minority tourism (Wong et al., 2019), coffee tourism (Wong et al., 2019) and local food (Sthapit et al., 2019), empirical studies that examine how CVT dimensions drive ME and its subsequent effects on tourists' attitudes and behavioural intention is still limited. As such, this study contributes to ME literature by providing empirical evidence to confirm the importance of price value, taste value, health value and emotional value in driving ME, which in turn strengthens tourists' satisfaction and revisit intention. The findings of this study also enhance the generalisability of ME by confirming the motivating factors driving ME and its subsequent outcomes. 


\section{Managerial implications}

The findings of this study provide several managerial implications. Firstly, managers of HKstyle cafes are recommended to improve the overall quality of tea beverages by collaborating with professionals of tea beverages, suppliers and distributors to offer tea beverages with delicious tastes appealing to tourists to provide a wonderful ME for tourists. Tourism marketers are also recommended to promote the appealing flavours of tea beverages to tourists by using a storytelling approach to create a ME.

Secondly, managers of HK-style cafes are suggested to demonstrate the hygiene and safety of the tea beverages by using open-kitchen designs, whereas the unclean tea beverages may formulate a poor traveling experience. In addition, tourism marketers are recommended to provide information about the nutritional value of the tea beverages and clearly state the ingredients.

Thirdly, tourism marketers are suggested to communicate the emotional value of tea beverages by emphasising that tea beverages offered by HK-style cafes can help tourists to be happy, relaxed and excited, which in turn offers an enjoyable experience for tourists. For example, café owners may consider designing the glass of tea beverages more attractive and funny or adding interactive features when drinking tea beverages.

Fourthly, tourism marketers are suggested to emphasise that tea beverages offered by HKstyle cafes are valuable and offer good value for money. This can be done by encouraging tourists to share their positive referrals and compare the price of tea beverages among Asian countries, such as Taiwan, China and Malaysia.

Lastly, tourism marketers are recommended to integrate consumption of HK-style tea beverages with other tourism activities. For instance, tourism marketers can prepare itineraries related to gastronomy and can offer opportunities for tourists to understand the meaning of local food and HK-style tea beverages, which can elevate their ME and satisfaction. Tourism marketers are also recommended to share information related to cultural meanings of HK-style tea beverages on websites, social media platforms and brochures to attract tourists to visit.

\section{Limitation and directions for future studies}

Despite the interesting findings, this study has several limitations. Firstly, this study only focussed on tourists visiting HK, thus limiting its generalisability. As tea beverages are offered in many destinations in Asia (e.g. Thailand, Taiwan and Malaysia), future studies are recommended to examine the perceived consumption value of tea beverages offered by these Asian countries to enhance the generalisability. Secondly, this study only focussed on Chinese tourists, and thus, the findings may be scant. Future studies could examine the perceptions of tourists of different nationalities or cultural backgrounds, such as the tourists' perception on tea beverages offered by HK-style cafes in the USA, Australia and the UK. Finally, the moderating effects of demographic variables are overlooked. As such, future studies are recommended to examine the moderating effects of demographic variables such as age, gender and income on the relationships between constructs in the research model.

\section{References}

Ahmad, M.S., Jamil, A., Latif, K.F., Ramayah, T., Leen, J.Y.A., Memon, M. and Ullah, R. (2019), "Using food choice motives to model Pakistani ethnic food purchase intention among tourists", British Food Journal, Vol. 122 No. 6, pp. 1731-1753.

Brislin, R. (1970), "Back-translation for cross-cultural research", Journal of Cross-Cultural Psychology, Vol. 1 No. 3, pp. 185-216. 
Chan, S.C. (2019), "Tea cafés and the Hong Kong identity: food culture and hybridity", China Information, Vol. 33 No. 3, pp. 311-328.

Chang, R.C., Kivela, J. and Mak, A.H. (2010), "Food preferences of Chinese tourists", Annals of Tourism Research, Vol. 37 No. 4, pp. 989-1011.

Cheng, S., Hu, J., Fox, D. and Zhang, Y. (2012), "Tea tourism development in Xinyang, China: stakeholders' view”, Tourism Management Perspectives, Vol. 2, pp. 28-34.

Cheng, S.W., Xu, F.F., Zhang, J. and Zhang, Y.T. (2010), "Tourists' attitudes toward tea tourism: a case study in Xinyang", Journal of Travel \& Tourism Marketing, Vol. 27 No. 2, pp. 211-220.

Cheung, S.C. (2013), "From foodways to intangible heritage: a case study of Chinese culinary resource, retail and recipe in Hong Kong", International Journal of Heritage Studies, Vol. 19 No. 4, pp. 353-364.

Choe, J.Y.J. and Kim, S.S. (2018), "Effects of tourists' local food consumption value on attitude, food destination image, and behavioral intention", International Journal of Hospitality Management, Vol. 71, pp. 1-10.

Cohen, J. (1988), Statistical Power Analysis for the Social Sciences, 2nd ed., Erlbaum, Hillsdale, NJ.

Gupta, V., Sajnani, M., Dixit, S.K. and Khanna, K. (2020), "Foreign tourist's tea preferences and relevance to destination attraction in India", Tourism Recreation Research, pp. 1-15.

Hair, J.F., Jr, Hult, G.T.M., Ringle, C. and Sarstedt, M. (2017), A Primer on Partial Least Squares Structural Equation Modeling (PLS-SEM), 2nd ed., Sage Publications, Thousand Oaks, CA.

Holbrook, M.B. (1999), "Introduction to consumer value", Consumer Value: A Framework for Analysis and Research, pp. 1-28

Jolliffe, L. (Ed.) (2007), Tea and Tourism: Tourists, Traditions and Transformations, Channel View Publications, Vol. 11

Kim, J.H. (2018), "The impact of memorable experiences on loyalty behaviors: the mediating effects of destination image and satisfaction", Journal of Travel Research, Vol. 57 No. 7, pp. 856-870.

Kim, S., Choe, J.Y. and Lee, S. (2018), "How are food value video clips effective in promoting food tourism? Generation Y versus non-generation Y", Journal of Travel \& Tourism Marketing, Vol. 35 No. 3 , pp. 377-393.

Kock, N. and Lynn, G. (2012), "Lateral collinearity and misleading results in variance-based SEM: an illustration and recommendations", Journal of the Association for Information Systems, Vol. 13 No. 7 , pp. 546-580.

Konuk, F.A. (2019), "The influence of perceived food quality, price fairness, perceived value and satisfaction on customers' revisit and word-of-mouth intentions towards organic food restaurants", Journal of Retailing and Consumer Services, Vol. 50, pp. 103-110.

Lai, I.K. (2015), "The roles of value, satisfaction, and commitment in the effect of service quality on customer loyalty in Hong Kong-style tea restaurants", Cornell Hospitality Quarterly, Vol. 56 No. 1, pp. 118-138.

Lai, I.K., Lu, D. and Liu, Y. (2019), "Experience economy in ethnic cuisine: a case of Chengdu cuisine", British Food Journal, Vol. 122 No. 6.

Mak, V.S.W. (2020), "The heritagization of milk tea: cultural governance and placemaking in Hong Kong", Asian Anthropology, Vol. 20 No. 1, pp. 1-17.

Mak, A.H., Lumbers, M., Eves, A. and Chang, R.C. (2012), "Factors influencing tourist food consumption", International Journal of Hospitality Management, Vol. 31 No. 3, pp. 928-936.

Mak, A.H., Lumbers, M., Eves, A. and Chang, R.C. (2013), "An application of the repertory grid method and generalised procrustes analysis to investigate the motivational factors of tourist food consumption", International Journal of Hospitality Management, Vol. 35, pp. 327-338.

Okumus, B. (2020), "Food tourism research: a perspective article", Tourism Review, Vol. 76 No. 1.

Podsakoff, P.M., MacKenzie, S.B., Lee, J.Y. and Podsakoff, N.P. (2003), "Common method biases in behavioral research: a critical review of the literature and recommended remedies", Journal of Applied Psychology, Vol. 88 No. 5, p. 879.

Rousta, A. and Jamshidi, D. (2020), "Food tourism value: investigating the factors that influence tourists to revisit", Journal of Vacation Marketing, Vol. 26 No. 1, pp. 73-95. 
Sheth, J.N., Newman, B.I. and Gross, B.L. (1991), "Why we buy what we buy: a theory of consumption values", Journal of Business Research, Vol. 22 No. 2, pp. 159-170.

Shmueli, G., Sarstedt, M., Hair, J.F., Cheah, J.H., Ting, H., Vaithilingam, S. and Ringle, C.M. (2019), "Predictive model assessment in PLS-SEM: guidelines for using PLSpredict", European Journal of Marketing, Vol. 53 No. 11, pp. 2322-2347.

Sthapit, E., Coudounaris, D.N. and Björk, P. (2019), "Extending the memorable experience construct: an investigation of memories of local food experiences", Scandinavian Journal of Hospitality and Tourism, Vol. 19 Nos 4/5, pp. 333-353.

Su, M.M., Wall, G. and Wang, Y. (2019), "Integrating tea and tourism: a sustainable livelihoods approach", Journal of Sustainable Tourism, Vol. 27 No. 10, pp. 1591-1608.

Sweeney, J.C. and Soutar, G.N. (2001), "Consumer perceived value: the development of a multiple item scale”, Journal of Retailing, Vol. 77 No. 2, pp. 203-220.

Textor (2020), "Number of outbound tourists departing from China from 2010 to 2019", accessed on 24 January 2021, available at: www.statista.com/statistics/1068495/china-number-of-outbound-touristnumber/\#: : text=In\%202019\%2C\%20the\%20number\%20of,from\%20other\%20countries\%20in\%202019

Tse, T.S. and Zhang, E.Y. (2013), "Analysis of blogs and microblogs: a case study of Chinese bloggers sharing their Hong Kong travel experiences", Asia Pacific Journal of Tourism Research, Vol. 18 No. 4, pp. 314-329.

Wang, M.J., Chen, L.H., Su, P.A. and Morrison, A.M. (2019), "The right brew? An analysis of the tourism experiences in rural Taiwan's coffee estates”, Tourism Management Perspectives, Vol. 30, pp. 147-158.

Wong, J.W.C., Lai, I.K.W. and Tao, Z. (2019), "Memorable ethnic minority tourism experiences in China: a case study of Guangxi Zhuang Zu", Journal of Tourism and Cultural Change, Vol. 17 No. 4, pp. 508-525.

Wong, J.W.C., Lai, I.K.W. and Tao, Z. (2020), "Sharing memorable tourism experiences on mobile social media and how it influences further travel decisions", Current Issues in Tourism, Vol. 23 No. 14, pp. 1773-1787.

Yeap, J.A., Ong, K.S.G., Yapp, E.H. and Ooi, S.K. (2019), "Hungry for more: understanding young domestic travellers' return for Penang street food", British Food Journal, Vol. 122 No. 6, doi: 10.1108/BFJ09-2018-0632.

Zeithaml, V.A. (1988), "Consumer perceptions of price, quality, and value: a means-end model and synthesis of evidence", Journal of Marketing, Vol. 52 No. 3, pp. 2-22.

Zhang, M., Kim, P.B. and Goodsir, W. (2019), "Effects of service experience attributes on customer attitudes and behaviours: the case of New Zealand café industry", Journal of Hospitality Marketing \& Management, Vol. 28 No. 1, pp. 28-50.

\section{Further reading}

Chin, W. (1998), "The partial least squares approach for structural equation modelling", in Marcoulides, G. (Ed.), Modern Methods for Business Research, Mahwah, NJ, Laurence Erlbaum Associates, pp. 295-336. 
Appendix 1

\section{Table A1 Respondents' demographic profile}

Variables

Descriptions

(\%)

Gender

Female

60.9

Male

39.1

Age

18-21 years old

9.3

22-25 years old

14.2

26-29 years old

38.2

30-33 years old

30.2

34-37 years old

7.1

38-40 years old

0.9

Primary school

3.1

High school

15.6

Bachelor

39.6

Postgraduate

41.7

Less than $\mathrm{RMB} \$ 3,500$

1.8

$\mathrm{RMB} \$ 3,500-\mathrm{RMB} \$ \$ 4,000$

7.6

$\mathrm{RMB} \$ 4,001-\mathrm{RMB} \$ \$ 4,500$

5.8

RMB $\$ 4,501-R M B \$ 5,000$

16.4

RMB $\$ 5,001-R M B \$ \$ 5,500$

9.3

RMB $\$ 5,501-R M B \$ \$ 6,000$

11.1

RMB $\$ 6,500$ or above

48.0

Objective of visiting HK

Visiting friends or relatives

Business

Relaxing

74.7

Shopping

18.7

Studying 


\section{Appendix 2}

\section{Table A2 PLS predict assessment}

\begin{tabular}{|c|c|c|c|c|c|c|c|}
\hline \multirow[b]{2}{*}{ Indicators } & \multicolumn{2}{|c|}{ PLS } & \multicolumn{2}{|c|}{$L M$} & \multicolumn{2}{|c|}{ PLS-LM } & \multirow[b]{2}{*}{$\begin{array}{l}\text { Decision of } \\
\text { predictive relevance }\end{array}$} \\
\hline & RMSE & $Q^{2}{ }_{\text {_predict }}$ & RMSE & $Q^{2} \_$predict & RMSE & $Q^{2} \_$predict & \\
\hline ME1 & 0.742 & 0.125 & 0.74 & 0.13 & 0.002 & -0.005 & Moderate \\
\hline ME2 & 1.03 & 0.133 & 1.051 & 0.097 & -0.021 & 0.036 & \\
\hline ME3 & 1.046 & 0.117 & 1.066 & 0.083 & -0.02 & 0.034 & \\
\hline Sat1 & 0.724 & 0.078 & 0.721 & 0.085 & 0.003 & -0.007 & Moderate \\
\hline Sat2 & 0.931 & 0.088 & 0.95 & 0.049 & -0.019 & 0.039 & \\
\hline Sat3 & 0.875 & 0.095 & 0.88 & 0.085 & -0.005 & 0.01 & \\
\hline Revisit1 & 0.809 & 0.051 & 0.812 & 0.045 & -0.003 & 0.006 & Strong \\
\hline Revist2 & 1.102 & 0.081 & 1.138 & 0.02 & -0.036 & 0.061 & \\
\hline Revist3 & 1.003 & 0.058 & 1.044 & -0.019 & -0.041 & 0.077 & \\
\hline Revisit4 & 1.003 & 0.055 & 1.039 & -0.013 & -0.036 & 0.068 & \\
\hline
\end{tabular}

\section{Corresponding author}

Man Lai Cheung can be contacted at: manlaiicheung@gmail.com

For instructions on how to order reprints of this article, please visit our website: www.emeraldgrouppublishing.com/licensing/reprints.htm

Or contact us for further details: permissions@emeraldinsight.com 